\title{
ANALISIS PENGARUH RETURN ON ASSETS (ROA), KEPEMILIKAN ASING DAN EARNING PER SHARE (EPS) TERHADAP PERKEMBANGAN HARGA SAHAM
}

(Studi Empiris Pada Perusahaan Real Estate Yang Terdaftar di BEI Tahun 20102012)

\author{
Sri Rahayu ${ }^{I}$ \\ Christien Setiya Kesumawati ${ }^{2}$ \\ Chintia Ayu Wulanda ${ }^{3}$ \\ Dosen Univ Budi Luhur ${ }^{1}$, Dosen Perguruan Tinggi Raharja ${ }^{2}$, Mahasiswa Univ Budi Luhur ${ }^{3}$ \\ Jl. Ciledug Raya, RT.10/RW.2, Petukangan Utara, Pesanggrahan, Jakarta Selatan ${ }^{1,3}$ Jl. Jendral Sudirman \\ No. 40, Modern Cikokol, Tangerang ${ }^{2}$ \\ Email : $\underline{\text { ayu72bl@yahoo.com }}{ }^{1)}, \underline{\text { ckesumawatil@yahoo.com }^{2)}}{ }^{\text {Chintia@yahoo.com }}{ }^{3)}$
}

\begin{abstract}
ABSTRAK
Penelitian ini bertujuan untuk memperoleh bukti empiris mengenai pengaruh roa, kepemilikan asing dan eps terhadap return saham baik secara parsial maupun simultan. Penelitian dilakukan pada di 10 perusahaan real estate dan properti yang terdaftar di Bursa Efek Indonesia periode 2010 - 2012. Pada penelitian ini terdapat 3 variabel yaitu roa, kepemilikan asing, dan eps sebagai variabel independen dan perkembangan harga saham sebagai variabel dependen. Hasil penelitian ini menunjukkan bahwa (1) ROA secara parsial tidak berpengaruh secara signifikan terhadap Perkembangan harga saham; (2) Kepemilikan asing secara parsial berpengaruh secara signifikan terhadap Perkembangan harga saham; (3)EPS secara parsial berpengaruh secara signifikan terhadap Perkembangan harga saham; (4)roa, kepemilikan asing, dan eps secara simultan berpengaruh terhadap Perkembangan harga saham.
\end{abstract}

Kata Kunci : Perkembangan Harga Saham, Return On Assets (ROA), Kepemilikan Asing, Earning Per Share (EPS).

\begin{abstract}
This research aimed to get empirical evidence about the influence of roa, foreign ownership and eps to stock return either partially or simultaneously. The study was conducted on 10 companies in real estate and properties listed in Indonesia Stock Exchange period 2010 - 2012. In this study, there are three variables: roa, foreign ownership, and eps as independent variables and the development of the share price as the dependent variable. The results of this study indicate that (1) ROA partially not significantly affect the development of the share price; (2) partial foreign ownership significantly influence the development of the share price; (3) EPS by partial significantly influence the development of the share price; (4) roa, foreign ownership, and eps simultaneously affect the stock price developments.
\end{abstract}

Keywords: Development of Share Price Return On Assets (ROA), Foreign Ownership, Earning Per Share (EPS).

\section{PENDAHULUAN}

\section{Latar Belakang Penelitian}

Dunia usaha di Indonesia sebagian besar terdiri dari usaha mikro, kecil dan menengah. Tujuan utama dari didirikannya perusahaan adalah untuk meningkatkan kesejahteraan 
pemegang saham atau pemilik perusahaan. Kesejahteraan dapat ditingkatkan melalui kinerja perusahaan yang baik. Kinerja perusahaan yang baik juga bermakna bagi konsumen, komunitas, karyawan, dan pemilik perusahaan dengan tujuan agar tercapainya kesejahteraan. Setiap perusahaan baik yang berskala besar maupun berskala kecil dibentuk untuk menghasilkan keuntungan, sehingga diharapkan akan berdampak pada kelangsungan hidup perusahaan dan masyarakat luas. Guna mempertahankan kelangsungan hidup perusahaan di tengah kerasnya persaingan bisnis yang ketat, perusahaan haruslah memiliki strategi yang tepat dan terintegrasi dengan baik sesuai karakternya. Perusahaan yang tepat memilih strategi akan dapat mempertahankandan mengungguli persaingan dalam pertumbuhan dan menghasilkan keuntungan serta mampu bertahan dalam siklus kehidupan bisnis dalam jangka waktu yang cukup panjang.

Hargasaham \& volume sahampadasektor PropertidanReal Estaterelative terustumbuhmeskipunadapenurunanpadatahun 2008 dan 2011. Haltersebut, terjadikarenaberbagaifactorbaikfaktor internal di suatuperusahaanmaupunfaktor eksternal, salahsatunyadarikondisiekonomi di suatu Negara sepertigejolakkrisisekonomi yang terjadi di tahun 2008, namun padatahun 2006, 2007, 2009 dan 2010 mulaiterjadipeningkatanpadasektor Properti dan Real Estate, dalamhalinitidakterlepas peran investor baikdaridalammaupundariluarnegeri yang masihmengalirkandananyapadabisnis Properti dan Real Estate yang nantinyaakanmenaikkankinerjakeuanganmelaluiprofitabilitasperusahaan. Pandanganpara investor asingmengenaiinvestasipadabisnisiniakanmemberikanreturn yang lebih menjanjikan.

\section{Batasan Masalah}

Dalam penelitian kali ini perlu adanya beberapa batasan masalah agar penelitian ini lebih terarah. Adapun beberapa batasan masalah dalam penelitian ini meliputi :

1. Variabel yang digunakan pada penelitian ini, Perkembangan Harga Saham(Y), Return On Assets $\left(\mathrm{X}_{1}\right)$, Kepemilikan Asing $\left(\mathrm{X}_{2}\right)$ dan Earning Per Share $\left(\mathrm{X}_{3}\right)$.

2. Obyek penelitian yang digunakan dalam penelitian ini adalah laporan keuangan perusahaan Real Estate yang terdaftar di Bursa Efek Indonesia tahun 2010 - 2012.

3. Perusahaan Real Estate yang memiliki data Kepemilikan Asing.

\section{Hipotesis}

Hipotesis alternatif yang diajukan adalah:

$\mathrm{Ho}_{1}$ : Tidak terdapat pengaruh Return On Assets (ROA) terhadap perkembangan harga saham.

$\mathrm{Ha}_{1}$ : Terdapat pengaruh Return On Assets (ROA) terhadap perkembangan harga saham.

$\mathrm{Ho}_{2}$ : Tidak terdapat pengaruh kepemilikan asing terhadap perkembangan harga saham.

$\mathrm{Ha}_{2}$ : Terdapat pengaruh kepemilikan asing terhadap perkembangan harga saham.

$\mathrm{Ho}_{3}$ : Tidak terdapat pengaruh Earning Per Share (EPS) terhadap perkembangan harga saham.

$\mathrm{Ha}_{3}$ : Terdapat pengaruh Earning Per Share (EPS) terhadap perkembangan harga saham.

$\mathrm{Ho}_{4}$ : Tidak terdapat pengaruh Return On Assets (ROA), kepemilikan asing, dan Earning Per Share (EPS) terhadap perkembangan harga saham.

$\mathrm{Ho}_{4}$ : Terdapat pengaruh Return On Assets (ROA), kepemilikan asing, dan Earning Per Share (EPS) terhadap perkembangan harga saham. 


\section{Kerangka Berpikir}

Penelitian bertujuan untuk memperoleh bukti mengenai pengaruh Return On Assets (ROA), kepemilikan asing, dan Earning Per Share (EPS) terhadap perkembangan harga saham. Data yang digunakan dalam penelitian merupakan data sekunder pada perusahaan manufaktur yang terdaftar di BEI.Dari teori tersebut terbentuk sebuah fenomena, yaitu fenomena teoritis dan fenomena situasional. Fenomena teoritis merupakan fenomena yang didasarkan pada buku, sedangkan fenomena situasional didasarkan pada kenyataan atau realita yang terjadi. Fenomena-fenomena ini kemudian akan menimbulkan rumusan masalah dan hipotesis. Berdasarkan fenomena tersebut, penelitian ini difokuskan pada pengaruh Return On Assets (ROA), kepemilikan asing, dan Earning Per Share (EPS) terhadap perkembangan harga saham.

Dengan variabel dependen dalam penelitian ini adalah perkembangan harga saham.Sedangkan variabel independen dalam penelitian ini adalah Return On Assets (ROA), kepemilikan asing, dan Earning Per Share (EPS).

\section{Metode Penelitian}

Teknik analisa data yang digunakan untuk membuktikan hipotesis adalah metode statistik regresi linear berganda. Dimana uji regresi berganda adalah alat analisis peramalan nilai pengaruh dua variabel bebas atau lebih terhadap satu variabel terikat untuk membuktikan ada atau tidaknya hubungan fungsional atau hubungan kausal antara dua atau lebih variabel bebas. Dalam penelitian ini untuk persamaan regresi berganda dirumuskan sebagai berikut :

\begin{tabular}{cll|}
\cline { 2 - 3 } $\operatorname{cimana}$ & & $\mathrm{Y}=\mathrm{a}+\mathrm{b}_{1} \mathrm{X}_{1}+\mathrm{b}+{ }_{2} \mathrm{X}_{2}+\mathrm{b}_{3} \mathrm{X}_{3+} \mathrm{e}$ \\
$\mathrm{n}$ & $=$ & Perkembangan harga saham \\
$\mathrm{a}$ & $=$ & Konstanta \\
$\mathrm{b}_{1}, \mathrm{~b}_{2}, \mathrm{~b}_{3}$ & $=$ & Koefisien Regresi masing-masing variabel independen \\
$\mathrm{x}_{1}$ & $=$ & Return on Assets \\
$\mathrm{X}_{2}$ & $=$ & Kepemilikan Asing \\
$\mathrm{X}_{3}$ & $=$ & Earning Per Share \\
$\mathrm{e}$ & $=$ & Error
\end{tabular}

Pengujian hipotesis dilakukan dengan uji t dan uji F. Namun sebelum meregresi data, dilakukan uji asumsi klasik regresi terlebih dahulu agar model regresi dapat menghasilkan penduga yang tidak bias, terdiri dari uji normalitas, heterokedastisitas, multikoleniaritas dan autokorelasi.

\section{Perkembangan Harga Saham}

\section{KAJIAN TEORI}

Perkembangan harga saham secara teoritis bermula dari aktivitas para pemodal (investor) mengestimasi pendapatan dan resiko untuk menentukan nilai saham dengan menggunakan data histories perusahaan. Hasil revaluasi ini akan dibandingkan dengan harga saham dan selanjutnya akan digunakan sebagai dasar pengambilan keputusan atas saham. Perkembangan harga saham merupakan harga penutupan dari masing-masing perusahaan pada suatu tahun penelitian dengan satuan ukuran rupiah. Harga saham yang dimaksud dalam penelitian ini adalah harga penutupan (closing price) karena harga inilah yang menyatakan naik turunnya suatu saham.Perkembangan harga saham dapat dirumuskansebagai berikut : 


\section{$\Delta$ Harga Saham $=\mathbf{P t}_{\mathbf{t}}-\mathbf{P}_{\mathrm{t}-1}$}

Sumber : Purwasih (2010:61)

Keterangan :

$\square$ HS : Perkembangan harga saham waktu $t$

Pt : Harga penutupan saham pada waktu $t$

Pt-1 : Harga penutupan saham pada waktu t-1

\section{Return On Assets (ROA)}

Menurut Wibowo dan Arif (2003:143): "ROA atau disebut juga hasil pengembalian atas harta merupakan perbandingan antara laba bersih dengan jumlah harta rata-rata." ROA merupakan ukuran tingkat profitabilitas diukur dari jumlah harta yang dimiliki. Sebuah perusahaan memiliki tujuan atau target dalam melakukan usahanya untuk mendapatkan laba. Alasan perusahaan mencapai laba agar dapat memenuhi kewajiban terhadap pemegang saham, penilaian atas kinerja pimpinan, dan meningkatkan daya tarik investor untuk menanamkan modalnya.Return On Assets(ROA) dapat dihitung menggunakan rumus sebagai berikut :

Return on Assets $=\frac{\text { Net Income }}{\text { Total Assets }}$

\section{Kepemilikan Asing}

Sumber : Irham Fahmi (2011: 28)

Kepemilikan asing merupakan kepemilikan saham yang dimiliki oleh perusahaan multinasional.Menurut Samsul (2007:99), "Kepemilikan asing merupakan kepemilikan saham oleh manajemen perusahaan yang diukur dengan prosentase jumlah saham yang dimiliki investor asing". Menurut Dian (2007:155), "Kepemilikan asing adalah orang perseorangan atau badan yang merupakan warga negara asing atau badan hukum asing yang menanamkan modalnya di dalam negeri”.Rumus untuk menghitung kepemilikan asing :

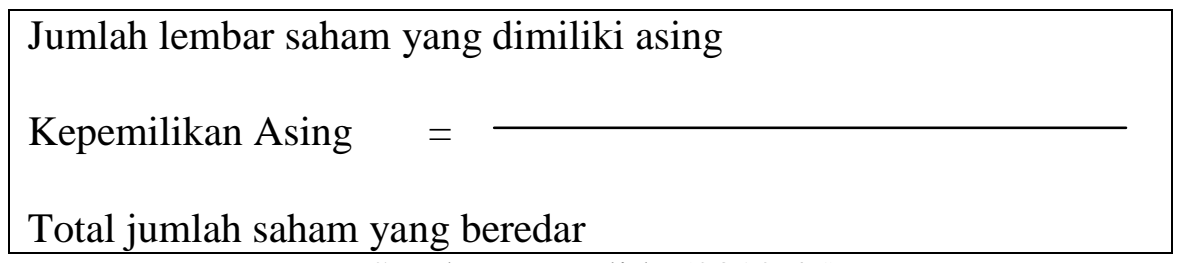

\section{Earning Per Share (EPS)}

Sumber : Maulida (2012:45)

Menurut Siamat (2005:519) : "Rasio ini menunjukan laba bersih yang berhasil diperoleh perusahaan untuk setiap unit saham selama suatu periode tertentu".Menurut Syamsuddin (2007:66) : "Pada umumnya manajemen perusahaan, pemegang saham dan calon pemegang saham sangat tertarik akan Earning Per Share (EPS), karena hal ini menggambarkan jumlah rupiah yang diperoleh untuk setiap lembar saham biasa. Para calon pemegang saham tertarik dengan Earning Per Share yang besar, karena hal ini merupaka salah satu indikator keberhasilan suatu perusahaan.Earning Per Share (EPS) dapat dihitung dengan menggunakan rumus sebagai berikut : 


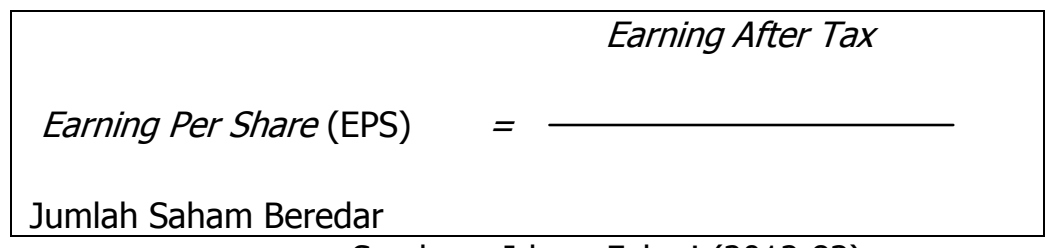

Sumber : Irham Fahmi (2012:83)

\section{OBJEK PENELITIAN}

Populasi penelitian yang digunakan dalam penelitian ini adalah perusahaan Real Estate yang terdaftar pada Bursa Efek Indonesia selama periode 2010 - 2012. Ringkasan prosedur pemilihan sampel dapat di lihat pada tabel dibawah ini:

\section{Tabel 1}

\section{Prosedur Pemilihan Sampel}

\begin{tabular}{|l|l|c|}
\hline No. & \multicolumn{1}{|c|}{ Kriteria } & Jumlah \\
\hline 1. & $\begin{array}{l}\text { Perusahaan Real Estate yang terdaftar pada Bursa Efek Indonesia } \\
\text { periode 2010 - 2012. }\end{array}$ & 48 \\
\hline 2. & $\begin{array}{l}\text { Perusahaan Real Estateyang tidak memilikikepemilikan asing } \\
\text { selama periode pengamatan. }\end{array}$ & (16) \\
\hline 3. & $\begin{array}{l}\text { Perusahaan Real Estateyang tidak konsisten dalam memiliki nilai } \\
\text { saham yang terus meningkat selama periode pengamatan. }\end{array}$ \\
\hline \multicolumn{1}{|c|}{ Jumlah Sampel } & 10 \\
\hline
\end{tabular}

\section{HASIL DAN PEMBAHASAN}

\section{Hasil Uji Normalitas}

One-Sample Kolmogorov-Smirnov Test

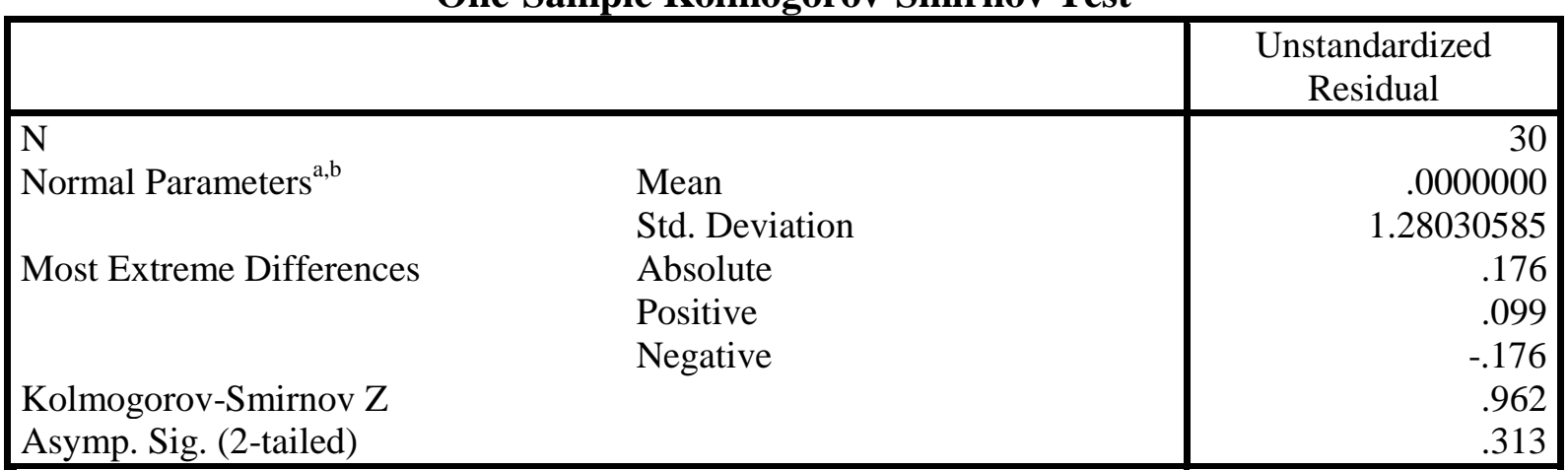

a. Test distribution is Normal.

b. Calculated from data.

Dari table One-Sample Kolmogorov-Smirnov Test, hasil pengolahan data diperoleh bahwa data dalam penelitian ini terdistribusi secara normal, karena nilai Asymp. Sig (2-tailed) 
bernilai 0.313 atau lebih besar dari $0.05(0.313>0.05)$.Maka Ho diterima yaitu data berasal dari populasi yang berdistribusi normal.

\section{Hasil Uji Multikoleniaritas}

\begin{tabular}{|c|c|c|c|c|c|c|c|}
\hline \multirow[b]{3}{*}{ Model } & \multicolumn{4}{|c|}{ Coefficients ${ }^{\mathrm{a}}$} & & \multirow{2}{*}{\multicolumn{2}{|c|}{$\begin{array}{l}\text { Collinearity } \\
\text { Statistics }\end{array}$}} \\
\hline & $\begin{array}{r}\text { Unst } \\
\text { Co }\end{array}$ & $\begin{array}{l}\text { ndardized } \\
\text { fficients }\end{array}$ & $\begin{array}{l}\text { Standardized } \\
\text { Coefficients }\end{array}$ & & & & \\
\hline & $\mathrm{B}$ & Std. Error & Beta & $\mathrm{t}$ & Sig. & Tolerance & VIF \\
\hline 1 (Constant) & .751 & .979 & & .768 & .449 & & \\
\hline Return On Asset & .142 & .125 & .267 & 1.134 & .267 & .360 & 2.779 \\
\hline Kepemilikan Asing & .036 & .016 & .363 & 2.209 & .036 & .737 & 1.356 \\
\hline Earning Per Share & .719 & .323 & .565 & 2.226 & .035 & .310 & 3.225 \\
\hline
\end{tabular}

a. Dependent Variable: Perkembangan Harga Saham

Dari hasil diatas dapat diketahui nilai Variance Inflation Factor (VIF) masing-masing variabel yaitu Return On Asset (ROA) adalah 2.779, Kepemilikan asing adalah 1.356, dan Earning Per Share (EPS) adalah 3.225. Ketiganya lebih kecil dari 10, dan nilai tolerance ketiga variabel tersebut tidak kurang dari 0,1 maka Ho diterima. Sehingga dapat disimpulkan bahwa antar variabel independen tidak terjadi persoalan multikolinearitas.

\section{Hasil Autokorelasi}

\begin{tabular}{|l|r|r|r|r|r|}
\hline Model & R & R Square & $\begin{array}{c}\text { Adjusted R } \\
\text { Square }\end{array}$ & $\begin{array}{c}\text { Std. Error of the } \\
\text { Estimate }\end{array}$ & Durbin-Watson \\
\hline 1 & $.694^{\mathrm{a}}$ & .481 & .421 & 1.35215 & 2.139 \\
\hline
\end{tabular}

a. Predictors: (Constant), Return On Asset, Kepemilikan Asing, Earning Per Share

b. Dependent Variable: Perkembangan Harga Saham

Dari tabel diatas didapat hasil angka Durbin-Watson sebesar 2.139. Dengan jumlah variabel independen atau $\mathrm{k}=3$ dan jumlah data atau $\mathrm{n}=30$, maka dari tabel $\mathrm{DW}$ didapat hasildl=1.006 dan du=1.421. Karena hasil du $<$ DW $<4$-dl $(1.421<2.139<2.994)$ maka dapat disimpulkan bahwa tidak terjadi autokorelasi. 


\section{Hasil Uji Heterokedastisitas}

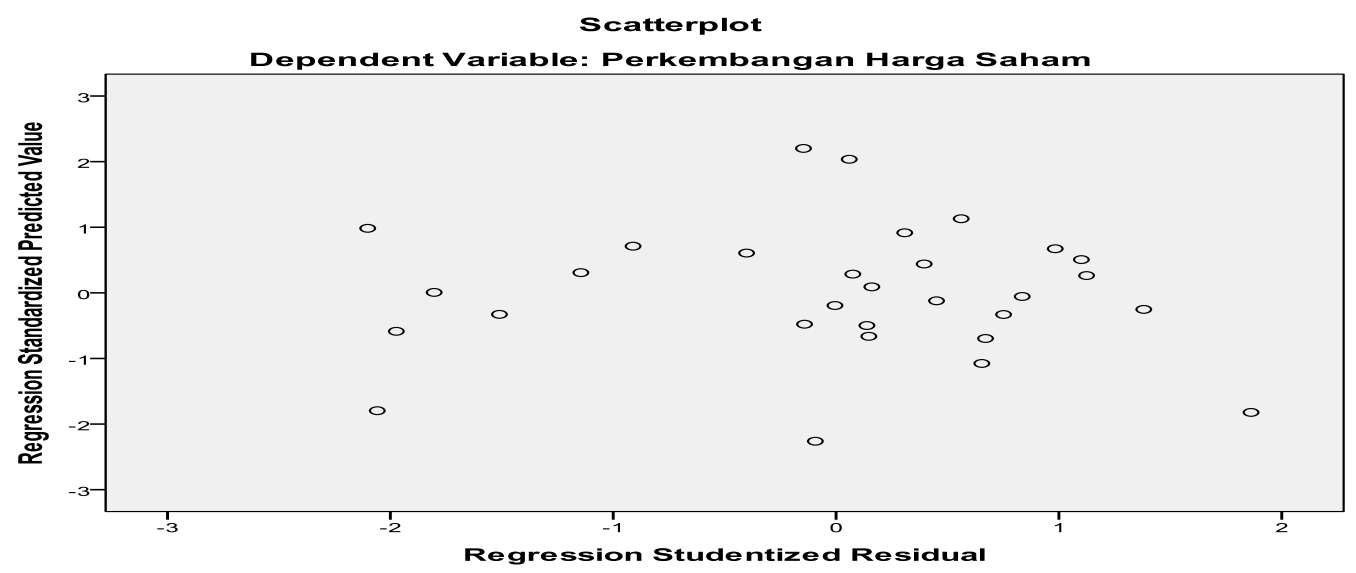

Gambar Scatterplot Hasil Uji Heterokedastisitas

Dari grafik scatterplot diatas terlihat bahwa titik-titik menyebar secara acak, tidak membentuk sebuah pola tertentu yang jelas, serta tersebar baik diatas maupun dibawah angka 0 pada sumbu Y. Maka dapat disimpulkan bahwa tidak terjadi heterokedastisitas pada model regresi ini, sehingga model regresi layak digunakan.

Hasil Regresi Linear Berganda

Hasil Garis Regresi

Coefficients $^{\mathrm{a}}$

\begin{tabular}{|c|c|c|c|c|c|c|c|c|}
\hline \multirow{2}{*}{\multicolumn{2}{|c|}{ Model }} & \multicolumn{2}{|c|}{$\begin{array}{c}\text { Unstandardized } \\
\text { Coefficients }\end{array}$} & \multirow{2}{*}{$\begin{array}{c}\begin{array}{c}\text { Standardiz } \\
\text { ed } \\
\text { Coefficients }\end{array} \\
\text { Beta }\end{array}$} & \multirow[b]{2}{*}{$\mathrm{T}$} & \multirow[b]{2}{*}{ Sig. } & \multicolumn{2}{|c|}{$\begin{array}{l}\text { Collinearity } \\
\text { Statistics }\end{array}$} \\
\hline & & $\mathrm{B}$ & Std. Error & & & & Tolerance & VIF \\
\hline \multirow[t]{4}{*}{1} & (Constant) & .751 & .979 & & .768 & .449 & & \\
\hline & Return On Asset & .142 & .125 & .267 & 1.134 & .267 & .360 & 2.779 \\
\hline & Kepemilikan Asing & .036 & .016 & .363 & 2.209 & .036 & .737 & 1.356 \\
\hline & Earning Per Share & .719 & .323 & .565 & 2.226 & .035 & .310 & 3.225 \\
\hline
\end{tabular}

a. Dependent Variable: Perkembangan Harga Saham

Sumber : Hasil Pengolahan Data Program SPSS 19.0

Berdasarkan tabel diatas dapat diketahui persamaan regresinya yaitu ;

$\mathrm{Y}=0.751+0.142 \times 1+0.036 \times 2+0.719 \times 3+\mathrm{e}$

Berdasarkan tabel diatas juga bisa kita simpulkan dimana variabel return on asset tidak memiliki pengaruh yang signifikan terhadap perkembangan harga saham karena memiliki nilai signifikansi lebih dari 0.05 . sedangkan variabel kepemilikan asing dan EPS memiliki pengaruh yang signifikan terhadap reaksi investor karena memiliki nilai signifikansi kurang dari 0.05 .

\section{Hasil Uji F}

ANOVA ${ }^{b}$

\begin{tabular}{|ll|r|r|r|r|r|}
\hline Model & & Sum of Squares & Df & Mean Square & F & Sig. \\
\hline 1 & Regression & 44.105 & 3 & 14.702 & 8.041 & $.001^{\mathrm{a}}$ \\
& Residual & 47.536 & 26 & 1.828 & & \\
& Total & 91.641 & 29 & & & \\
\hline
\end{tabular}




\begin{tabular}{|ll|r|r|r|r|r|}
\hline Model & & Sum of Squares & Df & Mean Square & F & Sig. \\
\hline 1 & Regression & 44.105 & 3 & 14.702 & 8.041 & $.001^{\text {a }}$ \\
& Residual & 47.536 & 26 & 1.828 & & \\
& Total & 91.641 & 29 & & & \\
\hline
\end{tabular}

a. Predictors: (Constant), Earning Per Share, Kepemilikan Asing, Return On Asset

b. Dependent Variable: Perkembangan Harga Saham

Dari uji ANOVA atau Uji $\mathrm{f}$ tersebut, $\mathrm{f}_{\text {hitung }}$ sebesar (8.041) sedangkan dengan tingkat signifikasi 5\% diperoleh $f_{\text {tabel }}$ sebesar 2.98. Dalam penelitian ini maka $f_{\text {tabel }}(8.041)>f_{\text {tabel }}$ (2.98) atau selain itu dari tabel ANOVA, dapat dilihat besar probabilitas yaitu 0.001. Karena signifikan penelitian lebih kecil dari $0.05(0.001<0.05)$, maka Ho ditolak dan Ha diterima, artinya terdapat pengaruh signifikan antara Return on Asset, Kepemilikan Asing, dan Earning Per Share terhadap Perkembangan HargaSaham.

\section{KESIMPULAN}

\section{Pengaruh Return On Assets(ROA) Terhadap Perkembangan Harga Saham}

Hasil penelitian menunjukkan bahwa Return On Asset (ROA) tidak memiliki pengaruh signifikan namun berkorelasi positif terhadap Perkembangan HargaSaham.Dalam penelitian kali ini ROA tidak memiliki pengaruh signifikan terhadap perkembangan harga saham. Hal ini bisa disebabkan karena para investor memandang bahwa ROA dari perusahaan yang dijadikan obyek penelitian tidak dapat menggambarkan secara utuh prospek keuntungan perusahaan tersebut.Jika kita melihat dari table deskripsi data, rata-rata keseluruhan ROA perusahaan yang dijadikan sampel juga cukup rendah bahkan mengalami penurunan diakhir tahun penelitian.Penelitian ini tidak konsisten dengan penelitian sebelumnya.Karena dalam penelitian kali ini ROA tidak memiliki pengaruh signifikan.

\section{Pengaruh Kepemilikan Asing Terhadap Perkembangan Harga Saham}

Hasil penelitian menunjukkan bahwa Kepemilikan Asing memiliki pengaruh signifikan yang positif terhadap Perkembangan HargaSaham.Kepemilikan asing merupakan kepemilikan saham oleh perusahaan asing yang diukur dengan prosentase jumlah saham yang dimiliki investor asing.Semakin besar kepemilikan asing sedikit banyak berpengaruh terhadap gambaran perusahaan di pasar modal.Karena perusahaan yang dimiliki oleh perusahaan asing dianggap lebih memiliki kredibilitas dan akuntabilitas yang baik dalam hal keuangan. Maka secara tidak langsung hal ini akan mempengaruhi permintaan akan saham perusahaan tersebut di pasar modal, dan dapat meningkatkan harga saham perusahaan tersebut. Penelitian kali ini tidak konsisten dengan penelitian sebelumnya karena dalam penelitian kali ini kepemilikan asing memiliki pengaruh signifikan.

\section{Pengaruh Earning Per Share (EPS)Terhadap Perkembangan Harga Saham}

Hasil penelitian menunjukkan bahwa Earning Per Share (EPS)memiliki pengaruh signifikan yang positif terhadap Perkembangan HargaSaham. Pada umumnya manajemen 
perusahaan, pemegang saham dan calon pemegang saham sangat tertarik akan Earning Per Share (EPS), karena hal ini menggambarkan jumlah rupiah yang diperoleh untuk setiap lembar saham biasa. Para calon pemegang saham tertarik dengan Earning Per Share (EPS) yang besar, karena hal ini merupakan salah satu indikator keberhasilan suatu perusahaan. Karena itulah EPS memiliki pengaruh signifikan terhadap perkembangan harga saham.Hasil penelitian kali ini konsisten dengan penelitian sebelumnya, karena dalam penelitian kali ini EPS memiliki pengaruh signifikan.

Ketiga variabel independen yang ditentukan merupakan bagian informasi keuangan yang dimiliki oleh perusahaan. Muatan informasi yang dimiliki oleh tiap-tiap variabel mempunyai arti penting tentang kinerja perusahaan dan juga informasi mengenai kondisi keuangan perusahaan. Semakin baik variabel independen yaitu Return On Asset, Kepemilikan Asing, dan Earning Per Share maka perusahaan tersebut akan dipandang semakin prospektif dan permintaan saham perusahaan tersebut akan semakin meningkat dan harga sahamnya akan semakin tinggi. Maka dapat disimpulkan bahwa ketiga variabel independen tersebut memiliki pengaruh signifikan terhadap variabel dependennya.

\section{Saran-Saran}

Bagi peneliti berikutnya yang akanmelakukanpenelitiandengan topik sejenisdisarankanhendaknyauntukmenambahkanjumlah sampel yang digunakan. Selain itu variable lain yang belumdimasukkankedalampenelitianinijuga bisa digunakan contohnya : ukuran perusahaan (size) dan kebijakanhutangperusahaan.Penelitianselanjutnyajugahendaknyamencobamenganalisa dengan sampel perusahaan yang heterogen.

\section{DAFTAR PUSTAKA}

[1] Brigham, F Eugene dan Joel F. Houston. 2010. Dasar-Dasar Manajemen Keuangan. Terj: Ali Akbar Yulianto. Edisi 2. Buku 1. Jakarta : Salemba Empat

[2] Dahlan Siamat. 2005. Managemen Lembaga Keuangan Kebijakan Moneter dan Perbankan. Edisi ke lima. Jakarta : Fakultas Ekonomi Universitas Indonesia

[3] Priyatno, Duwi. 2008. Mandiri Belajar SPSS. Yogyakarta: Mediakom

[4] Samsul, 2006. Pasar Modal \& Manajemen Portofolio, Edisi Pertama. Jakarta : Erlangga

[5] Sangadji, Etta Mamang, dan Sopiah. 2010. Metodologi Penelitian- Penedekatan Stattika dalam Penelitian.Edisi Pertama. Yogyakarta: CV Andi Offset

[6] Aziz Saleh, Volanda. 2012. Pengaruh Informasi Akuntansi Terhadap Perubahan Harga Saham Perusahaan Pertambangan Go Public Di Bursa Efek Indonesia. Tesis dipublikasikan. Universitas Lampung.

[7] Maulida, Dinda. 2012. Pengaruh Kepemilikan Asing, Afiliasi Asing, Dan Proyek Pemerintah Terhadap Luas Pengungkapan Tanggung Jawab Sosial Perusahaan (Studi Pada Perusahaan Yang Terdaftar Di Bei Tahun 2011). Tesisdipublikasikan. Universitas Diponegoro. 
[8] Purwasih, Ratna. 2010. Pengaruh Rasio Camel Terhadap Perubahan Harga Saham Perusahaan Perbankan Yang Go Public Di Bursa Efek Indonesia (Bei) Tahun 20062008. Tesisdipublikasikan. Universitas Diponegoro.

[9] Rahman, Harif. 2011. Pengaruh economic value added (EVA), return on asset (ROA), dan persentase kepemilkan modal saham asing terhadap harga saham pada perusahaan perbankan yang terdaftar di Bursa Efek Indonesia (BEI). Tesisdipublikasikan.Universitas Negeri Padang. 